\title{
Neuroticism and psychopathy predict brain activation during moral and nonmoral emotion regulation
}

\author{
Carla L. HaRenski \\ The MIND Research Network, Albuquerque, New Mexico \\ SANG Hee Kim \\ Seoul National University, Seoul, South Korea \\ AND \\ STEPHAN HamanN \\ Emory University, Atlanta, Georgia
}

\begin{abstract}
Functional neuroimaging has identified brain regions associated with voluntary regulation of emotion, including the prefrontal cortex and amygdala. The neural mechanisms underlying individual differences in emotion regulation have not been extensively studied. We investigated the neural correlates of neuroticism and psychopathic personality traits in the context of an emotion regulation task. Results showed that amygdala activity elicited by unpleasant pictures was positively correlated with neuroticism and negatively correlated with a specific psychopathic trait related to emotional underreactivity. During active attempts to decrease emotional responses to unpleasant pictures, superior and ventrolateral prefrontal activity was positively correlated with psychopathy, but not with neuroticism. In contrast, dorsolateral prefrontal activity was positively correlated with neuroticism, but not with psychopathy. Psychopathy was also negatively correlated with medial prefrontal activity in response to pictures depicting moral violations, suggesting reduced emotional responses to moral stimuli in individuals with high levels of psychopathic traits. These results demonstrate dissociable influences of different personality traits on neural activity associated with responses to emotional stimuli and on the recruitment of regulationrelated brain activity during the active down-regulation of responses to negative emotional stimuli. These results have implications for the etiology of trait-based psychopathology involving emotional dysregulation.
\end{abstract}

The ability to process and respond adaptively to emotion-inducing events and to appropriately integrate emotional experiences into daily life is of considerable importance for mental health and well-being (Baumeister \& Exline, 2000; Gross \& Munoz, 1995; Salovey, Hsee, $\&$ Mayer, 1993). These skills often require the ability to exercise voluntary control over one's emotions, a process that is developed and refined throughout childhood and adolescence. Yet there are substantial individual differences in the ability to regulate emotions effectively, even among adults (Gross \& John, 2003; Nolen-Hoeksema \& Corte, 2004). The consequences of ineffective or inappropriate emotional regulation can sometimes be minor-for example, leading to an argument with a friend. However, more marked dysregulation of emotions can contribute to the development of affective disorders, such as anxiety and depression (Garnefski, Kraaij, \& Spinhoven, 2001; Martin \& Dahlen, 2005).

Individual differences in the ability to regulate emotional responses may result from differences in the extent to which individuals experience emotions. For example, an unpleasant experience, such as a minor car accident, might cause a mild negative emotional response in one individual but might cause significant emotional distress to another individual. Individuals who tend to experience heightened emotional reactions to unpleasant events may also experience greater difficulty when down-regulating such reactions. In contrast, individuals who experience milder emotional responses to unpleasant events may be better able to down-regulate the emotional response to a more adaptive level or may not need to regulate their reaction, because an appropriate response has already been elicited. These individual differences in emotional reactivity and the ability to effectively modulate emotional responses carry significant implications for healthy psychological function and well-being. In the present study, we investigated two personality traits that have been shown to affect responses to emotional stimuli: neuroticism, which is associated with heightened reactivity to negative emotional stimuli (Costa \& McCrae, 1980; Larsen \& Ketelaar, 
1991), and psychopathic personality, which is associated with attenuated reactivity to negative emotional stimuli (Lykken, 1957; Patrick, 1994). We explored the association between these traits and neural responses during emotion processing and active down-regulation of emotional responses.

\section{Neuroticism and Increased Negative Affect}

Neuroticism is a personality trait associated with a greater tendency to experience negative affect (Costa \& McCrae, 1980; Larsen \& Ketelaar, 1991) and a diminished capacity to down-regulate negative emotions (Kokkonen \& Pulkkinen, 2001; Slessareva \& Muraven, 2004). Neuroticism has a prominent role in leading theories of personality (Costa \& McCrae, 1980; Eysenck, 1990; Gray, 1972) and has been implicated in several mood and personality disorders (Bienvenu \& Stein, 2003; Davidson, Miller, \& Strickland, 1985; Samuels et al., 2000). There has also been a growing interest in identifying patterns of brain activity that are associated with neuroticism, and it has even been suggested that neuroimaging techniques, such as functional magnetic resonance imaging (fMRI), might prove superior to behavioral methods in characterizing personality dimensions, including neuroticism (Canli \& Amin, 2002; Eisenberger, Lieberman, \& Satpute, 2005). The rationale for this view is that whereas behavioral measures can be considered to be the result of the combined patterns of all brain activity during a particular task, neuroimaging techniques can isolate specific patterns of brain activity during performance of the task of interest that have been proposed to be influenced by certain personality characteristics.

The neural correlates of neuroticism have been investigated within the context of several emotional and cognitive tasks. For example, Canli et al. (2001) reported positive correlations between neuroticism and activity in the dorsolateral prefrontal cortex (dlPFC) during an emotional picture viewing task. In a subsequent study that used an emotional Stroop task, negative mood, but not neuroticism, was positively correlated with anterior cingulate (ACC) activation to negative words (Canli, Amin, Haas, Omura, \& Constable, 2004). Given that negative mood is characteristic of individuals high in neuroticism, the latter study suggested that the effects of certain personality traits on brain activation might be related more to the mood state associated with the personality trait. Another study showed a negative correlation between neuroticism and ACC activation during a controlled processing (oddball detection) task (Eisenberger et al., 2005). Thus, associations between neuroticism and activity in prefrontal regions including the dlPFC and ACC have been found during emotional and cognitive tasks. These brain regions have also been consistently implicated in the neural basis of emotion regulation, such that voluntary attempts to modulate emotional responses lead to increased activity in these regions (Ochsner \& Gross, 2005). Moreover, increased prefrontal activity during attempts to down-regulate emotional responses has been shown to lead to behavioral reports of reduced emotional responses, as well as to decreased activity in emotion-processing regions such as the amygdala (Ochsner, Bunge, Gross, \& Gabrieli, 2002; Phan et al., 2005). Notably, this effect has been found particularly in the ventrolateral prefrontal cortex (vlPFC), suggesting that activity in this region is associated with successful down-regulation of emotional responses. In contrast, regulation-related activity in other prefrontal regions, such as the dlPFC, has not been associated with regulation success. In fact, Lévesque et al. (2003) found that dIPFC activity was positively correlated with emotion ratings during attempts to down-regulate emotional responses and suggested that activity in this region might represent effortful regulation, where activity increases with greater task difficulty. Consistent with this suggestion, Eippert et al. (2007) found a negative correlation between dlPFC activity during emotion regulation and postscan ratings of regulation success. Thus, if an individual has difficulty regulating emotional responses, one might expect to see increased dlPFC activity during regulation.

With these ideas in mind, we investigated whether neuroticism modulates brain activity when individuals attempt to exert voluntary control over emotional responses. We sought to determine whether higher levels of neuroticism correlated with increased activity in brain regions associated with emotional processing during emotional picture viewing and with increased activity in brain regions involved in effortful emotion regulation during active attempts to down-regulate emotional responses.

\section{Psychopathic Personality and Decreased Emotional Reactivity}

In addition to neuroticism, which is characterized by increased negative affect, we investigated a personality trait that is characterized by the opposite disposition: the tendency to experience reduced negative affect. Specifically, we investigated the association between neural responses during emotion processing and regulation and variation in psychopathic personality traits. Psychopaths show decreased autonomic reactivity to emotional stimuli, as compared with nonpsychopaths, particularly when the stimuli depict fearful or threatening content (Lykken, 1957; Patrick, 1994) or others in distress (Aniskiewicz, 1979; Blair, Jones, Clark, \& Smith, 1997), as well as impaired identification of fearful facial expressions and vocal expressions of fear (Blair, 1999; Blair et al., 2004; Blair, Mitchell, \& Richell, 2002). Neuroimaging studies have shown that psychopaths, relative to nonpsychopaths, show increased lateral and superior prefrontal activity (Gordon, Baird, \& End, 2004; Kiehl et al., 2001; Müller et al., 2003) and diminished limbic activity (Birbaumer et al., 2005; Gordon et al., 2004; Kiehl et al., 2001; but see Müller et al., 2003) to emotional stimuli, including unpleasant words or facial expressions. These findings indicate that psychopathy does not merely represent the "low end" of the normal spectrum of emotional reactiv- 
ity, but involves specific deficits in emotional responding that are not shown by nonpsychopaths and that are associated with reduced responses in brain regions associated with emotional processing. Thus, we investigated whether higher levels of psychopathic traits would predict decreased activity in brain regions associated with emotional processing during emotional picture viewing and regulation.

We also predicted that individuals higher in psychopathic traits would more easily regulate emotional responses to unpleasant stimuli, relative to those lower in psychopathic traits, since their emotional responses would be minimal. Accordingly, these individuals should show increased activity in brain regions involved in successful emotion regulation, such as the vlPFC, during active attempts to down-regulate emotional responses. We also predicted a positive association between psychopathic traits and activity in the superior prefrontal cortex during regulation. This region is one of the most consistently implicated regions in emotion regulation (Eippert et al., 2007; Harenski \& Hamann, 2006; Herwig et al., 2007; Kim \& Hamann, 2007; Ochsner et al., 2002; Ochsner et al., 2004; Phan et al., 2005), and although information on the role of this region in regulation is limited, a recent study by Herwig et al. (2007) showed increased activity in this region in an emotion regulation "expert" (a trained psychotherapist), and it was suggested that activity in this region might be related to the amount of training and expertise one has in regulating emotions. We expected that individuals high on psychopathic traits would resemble "experts" in regulating their emotional responses and would thus show increased superior prefrontal activity during regulation.

In summary, we investigated the association between neuroticism and psychopathic traits and regional brain activation, both during passive viewing of unpleasant pictures and during active down-regulation of emotional responses to unpleasant pictures. To assess neuroticism, we used the NEO Five Factor Inventory (NEO-FFI; Costa \& McCrae, 1992). To assess psychopathic personality traits, we used the Psychopathic Personality Inventory (PPI; Lilienfeld \& Andrews, 1996), a selfreport questionnaire that is designed to measure psychopathic traits in nonclinical populations. In addition to the total PPI score, which represents the combination of all psychopathic traits (e.g., egocentricity, manipulativeness, impulsivity), we explored the effects of the "Coldheartedness" subscale of the PPI, which focuses on low emotional reactivity, on brain activity during emotional picture viewing and regulation. We predicted that, when viewing unpleasant pictures, individuals high in neuroticism would show increased amygdala activity, relative to individuals low in neuroticism, representing heightened emotional responses. Prior research has demonstrated the role of the amygdala in the processing of negative emotional stimuli (Garavan, Pendergrass, Ross, Stein, \& Risinger, 2001; Hamann, Ely, Hoffman, \& Kilts, 2002; Isenberg et al., 1999; Strange, Henson, Friston, \& Dolan, 2000). In contrast, we predicted that individuals scor- ing high on psychopathic traits, particularly coldheartedness, would show decreased amygdala activity when viewing unpleasant pictures. Regarding the regulation of emotional responses to unpleasant pictures, we predicted that, during attempts to down-regulate negative emotions, individuals high in neuroticism would show increased dIPFC activity, representing increased difficulty in regulation, as compared with individuals low in neuroticism. In contrast, we predicted that individuals high in psychopathic traits and coldheartedness would show increased vlPFC and superior prefrontal activity, representing successful regulation, relative to individuals scoring low on these traits.

\section{Moral Versus Nonmoral Emotion Regulation}

To further explore the association between personality traits and emotion regulation, we compared the viewing of and regulation of emotional responses to two different types of emotional stimuli: moral and nonmoral pictures. Participants either passively viewed or regulated their emotional responses to unpleasant pictures that did or did not contain moral violations - for example, a picture of a drunk driver (moral picture) versus a picture of a driver displaying "road rage" (nonmoral picture). We were interested in exploring the association between psychopathic traits and emotional responses to unpleasant pictures depicting moral violations. Prior research has shown that psychopaths are more likely than nonpsychopaths to intentionally commit moral violations, such as stealing and violence against others, and to show a lack of remorse for such actions (Blair, 1997; Blair, Jones, Clark, \& Smith, 1995; Blair, Sellars, Strickland, \& Clark, 1995; Hare, 1998). Psychopathic individuals have also been shown to lack a sophisticated understanding of the distinction between moral and conventional transgressions (Blair, Jones, et al., 1995; Nucci \& Herman, 1982), suggesting a cognitive deficit that may contribute to immoral behavior.

Psychopathy, then, is characterized by moral insensitivity and deficits in broader emotional functioning. These two phenomena are not necessarily distinct. Moral violations often evoke emotional responses, and recent theories of moral appraisal have placed a greater emphasis on the role of emotions in guiding moral judgments (Haidt, 2001; Prinz, 2006). If psychopaths lack sufficient emotional responses, this may contribute to their insensitivity to moral violations. Although the neural correlates of emotional deficits in psychopathy have begun to be characterized (Blair, Mitchell, \& Blair, 2005; Kiehl, 2006), the neural correlates of moral processing in psychopathy have yet to be investigated.

Neuroimaging studies of healthy individuals have shown that viewing statements and/or pictures depicting moral violations activates brain regions involved in emotion processing, including the medial prefrontal cortex (MPFC) and, less consistently, the posterior cingulate (for reviews, see Greene \& Haidt, 2002; Moll, Zahn, de Oliveira-Souza, Krueger, \& Grafman, 2005). If psychopaths are less emotionally responsive to moral 
stimuli, they should show less activity in these brain regions during the viewing of such stimuli. The present study explored this hypothesis by investigating the association between psychopathic traits and neural activity during moral versus nonmoral picture viewing, as well as during active down-regulation of emotional responses to moral and nonmoral pictures. We predicted that individuals high in psychopathic traits would show less activity in the MPFC during moral picture viewing and regulation, relative to individuals low in psychopathic traits. Our hypothesis was based on previous research linking MPFC lesions to psychopathic-like behavior (Anderson, Bechara, Damasio, Tranel, \& Damasio, 1999) and impaired reasoning about affective aspects of moral dilemmas (Koenigs et al., 2007). We did not have specific predictions regarding neuroticism since, to our knowledge, no prior studies have linked neuroticism to moral (or nonmoral) processing.

Ten participants were scanned using fMRI while they passively viewed or attempted to decrease emotional responses to unpleasant pictures. Half of these pictures depicted moral violations, whereas the other half were thematically matched pictures that did not depict moral violations. We investigated correlations between neuroticism and psychopathic traits and regional brain activation, both during passive viewing of emotional pictures and during active down-regulation. We also investigated whether correlations between psychopathic traits, neuroticism, and brain activity differed for moral and nonmoral stimuli. Given the exploratory nature of our study due to the low sample size, we also conducted a second, event-related fMRI experiment in the same scanning session, in which the same participants viewed a different set of unpleasant pictures, selected to minimize moral salience, and again attempted to decrease their emotional responses. This additional experiment provided an opportunity to replicate the findings from the first experiment, thus minimizing the likelihood of spurious findings. The event-related design of the second experiment also enabled analysis of fMRI responses to each picture, and in addition, because participants provided online arousal ratings after each picture, regulation success could be assessed by examining the effect of regulation on online arousal ratings.

\section{EXPERIMENT 1}

\section{Method}

Participants. Ten right-handed female adults free from any history of neurological or psychiatric impairment, and of similar education level, were recruited (age range, 18-29 years). Only females were recruited because males and females have been suggested to differ in neural activity during emotion processing (for a review, see Hamann \& Canli, 2004). The participants provided written informed consent prior to the study, which was approved by the Emory University Institutional Review Board.

Stimuli and Design. Two sets of unpleasant pictures (32 moral, 32 nonmoral) were selected mostly from the International Affective Picture System (IAPS) (Lang, Bradley, \& Cuthbert, 1995) and were supplemented with pictures from the popular media. Moral pictures depicted unpleasant social scenes indicating a specific moral violation (e.g., an abusive situation). Nonmoral pictures depicted unpleasant social scenes without moral content (e.g., an argument). Moral and nonmoral pictures were matched for emotional arousal and social complexity on the basis of ratings provided in a prior pilot study of 25 participants (none of these participants were included in the present study). For more information on the pictures and the matching procedure, see Harenski and Hamann (2006).

At the beginning of each trial block, an instruction in white letters appeared in the center of a black screen for $8 \mathrm{sec}$. The instruction was either WATCH or DECREASE, indicating how the participant should evaluate the following group of pictures. On both watch and decrease trials, a set of four consecutive moral or nonmoral pictures was shown following the instruction, each picture shown for $5 \mathrm{sec}$, for a total of $28 \mathrm{sec}$ per trial. During watch trial blocks (four moral, four nonmoral), the participants were instructed to view the pictures and allow themselves to experience whatever thoughts or feelings each picture evoked. During decrease trial blocks (four moral, four nonmoral), the participants were instructed to view the pictures and attempt to decrease any elicited emotional responses by thinking about the picture in a way that rendered their responses less emotional. A baseline condition was included in which the participants viewed four consecutive single-digit numbers and covertly determined for each whether the number was odd or even. The 8 -sec instruction preceding these trials was ODD-EVEN. This task was used as a baseline instead of fixation, because it has been shown that engaging participants in a minimally demanding cognitive task results in less variable brain activation, allowing for a clearer contrast between baseline and active conditions (Stark \& Squire, 2001).

Procedure. One week prior to scanning, all the participants completed a practice session to become familiarized with the experimental task. In the task, the participants were presented with individual pictures and were instructed either to watch the picture or to attempt to decrease their emotional response. The participants were not directed to use any particular strategy in decreasing their emotional responses, to increase the ecological validity of the regulation processes; however, suggestions were given in the form of reappraising the picture so that it depicted a less negative emotional situation. For example, a car accident scene could be reinterpreted as a scene from a movie that was not real, as being viewed on the news as having occurred in another country (creating physical distance from the emotional event), or as happening to a person whom the individual had never met (creating interpersonal distance). The participants were instructed not to use a suppression strategy (e.g., controlling facial expressions). For a more detailed description of the practice session, see Harenski and Hamann (2006). A follow-up questionnaire at the end of the study indicated near unanimity across participants in using a reappraisal strategy of pretending that the scenes were unreal.

During scanning, the participants completed twenty 28-sec trials across two separate scan runs. Each of the five trial types (watch moral/nonmoral, decrease moral/nonmoral, and odd-even) occurred four times, and the order of trial types was counterbalanced across scans, so that no two trial types were presented in succession more than any other two trial types. In addition, pictures assigned to the watch condition were switched with those assigned to the decrease condition, creating a second stimulus set that was presented to every other participant (five total). Images were rear-projected using an LCD projector, controlled by a laptop computer. Tasks were designed and presented using Presentation software (Version .50; Neurobehavioral Systems, 2002, http://nbs .neuro-bs.com).

Personality measures. Prior to the scanning session, the participants completed two personality questionnaires: the NEO-FFI (Costa \& McCrae, 1992) and the PPI (Lilienfeld \& Andrews, 1996). The NEO-FFI measures five personality traits: neuroticism, extraversion, openness to experience, agreeableness, and conscientiousness. It consists of 60 items, 12 items addressing each trait. Items 
are rated on a scale of 1-5 (disagree strongly, disagree, neutral, agree, agree strongly). Because our study included only negative emotional stimuli, we were primarily interested in the influence of neuroticism on brain activity associated with regulating negative emotions. Representative neuroticism items include "I seldom feel blue" (reverse scored) and "I often get angry with the way people treat me."

The PPI (Lilienfeld \& Andrews, 1996) is designed to measure psychopathic personality traits in nonclinical populations. In addition to a total psychopathy score, it provides subscores on eight personality traits characteristic of psychopathy: Machiavellian egocentricity (sample item: "I always look out for my own interests before worrying about those of the other guy"), social potency (sample item: "Even when others are upset with me, I can usually win them over with my charm"), coldheartedness (sample item: "It bothers me greatly when I see someone cry"; reverse scored), carefree nonplanfulness (sample item: "I often make the same errors in judgment over and over again"), fearlessness (sample item: "Making a parachute jump would really frighten me"; reverse scored), blame externalization (sample item: "I usually feel that people give me the credit that I deserve"; reverse scored), impulsive nonconformity (sample item: "I sometimes question authority figures "just for the hell of it"'), and stress immunity (sample item: "I can remain calm in situations that would make many other people panic"). The questionnaire consists of 56 items, 8 items addressing each trait. Items are rated on a scale of 1-4 (false, mostly false, mostly true, true).

In addition to the NEO-FFI and PPI, 9 of the 10 participants completed the Positive and Negative Affect Scale (PANAS; Watson, Clark, \& Tellegen, 1988). The PANAS quantifies separate subscales related to positive mood and negative mood. Ratings were made on a scale ranging from 1 (very slightly) to 5 (extremely) regarding how the participant felt at that moment for a set of 20 terms (e.g., active, guilty, interested, hostile). Since prior research has shown that associations between neuroticism and neural activity during emotional and cognitive tasks may be due more to the negative mood state that is associated with high levels of neuroticism (Canli et al., 2004), negative mood state scores were included as a covariate for all neuroticism analyses.

MRI data acquisition. Whole-brain imaging data were obtained using a Siemens 3T Trio MRI scanner. Brain imaging involved acquisition of 30 axial slices of 3-mm thickness acquired parallel to the AC-PC line. Functional scans were acquired using $\mathrm{T} 2 *$-weighted gradient echo, echo-planar pulse sequences $(\mathrm{TR}=$ $2,516 \mathrm{msec}, \mathrm{TE}=30 \mathrm{msec}, 64 \times 64$ matrix, $3 \times 3 \times 3 \mathrm{~mm}$ voxel size). A total of 114 scans were obtained in each of two scan runs. Structural images were acquired using a gradient echo, T1weighted pulse sequence $(\mathrm{TR}=500 \mathrm{msec}, \mathrm{TE}=20 \mathrm{msec}, 256 \times$ 256 matrix, $1 \times 1 \times 1 \mathrm{~mm}$ voxel size). Head movement was limited by padding and restraint.

Data analysis. Functional images were motion corrected and normalized to a standard template brain using SPM99 (www.fil.ion .ucl.ac.uk/spm). Images were normalized to the standard template brain by applying a 12-parameter affine transformation, followed by nonlinear warping using basis functions, and were smoothed using a Gaussian kernel of 6-mm FWHM. Grand mean global scaling was used to correct for between-participant/session differences in mean signal intensity. Low-frequency noise was removed using a highpass filter (Holmes, Josephs, Büchel, \& Friston, 1997).

Individual participant data were analyzed using a fixed effects model (Friston, Jezzard, \& Turner, 1994). Group data were analyzed using a random effects model (Holmes \& Friston, 1998). Condition effects at the participant level were modeled by boxcar regressors representing the occurrence of each of the five block types, convolved with a canonical hemodynamic response function for the 20 -sec period during which the participants either passively viewed or decreased their emotional responses to the pictures or performed the baseline task. A thresholded gray matter mask $(80 \%$ of all gray matter) was specified during analysis to help minimize the loss of signal in brain regions that are susceptible to signal dropout. A voxel-level threshold of $p<.001$ with an extent threshold of 5 contiguous voxels was used for regions of a priori interest. These included regions associated with emotional processing (the amygdala) and emotion regulation (the superior frontal cortex [BA 6/8], the dIPFC [BA 8/9], and the vlPFC [BA 45/47]), as well as regions associated with affective aspects of moral processing (the MPFC [BA 9/10/11] and the posterior cingulate [BA 31]). Statistical results for all activation clusters identified within these regions of interest (ROIs) were corrected for multiple comparisons, using the SPM small-volume correction (Worsley et al., 1996) with a familywise error rate (FWE) of $p<.05$, using 10 -mm spherical regions with the central coordinates derived from averaged coordinates on the basis of previous emotion regulation studies reporting activations in the superior prefrontal cortex, dlPFC, and vlPFC (Eippert et al., 2007; Herwig et al., 2007; Lévesque et al., 2003; Ochsner et al., 2002; Ochsner et al., 2004; Phan et al., 2005). The same procedure was used for brain regions associated with moral processing (the MPFC and posterior cingulate), in which coordinates were obtained from previous morality studies reporting activations in these regions (Greene, Nystrom, Engell, Darley, \& Cohen, 2004; Greene, Sommerville, Nystrom, Darley, \& Cohen, 2001; Heekeren et al., 2005; Heekeren, Wartenburger, Schmidt, Schwintowski, \& Villringer, 2003; Moll, de Oliveira-Souza, Bramati, \& Grafman, 2002; Moll, de Oliveira-Souza, Eslinger, et al., 2002; Moll et al., 2005; Robertson et al., 2007; Schaich Borg, Hynes, Van Horn, Grafton, \& Sinnott-Armstrong, 2006). For the amygdala, an 8-mm spherical region was used with the central coordinates determined on the basis of prior research in our laboratory focused on this region (Hamann et al., 2002; Hamann \& Mao, 2002).

To identify regions that were correlated with individual participant personality scores, activated regions were identified in specific contrasts corresponding to hypotheses regarding unpleasant picture viewing (watch moral $>$ odd-even, watch nonmoral $>$ odd-even) and emotion regulation (decrease moral $>$ watch moral, decrease nonmoral $>$ watch nonmoral), as well as those regarding moral versus nonmoral processing (watch moral $>$ watch nonmoral, and watch nonmoral $>$ watch moral). For activations in ROIs for which we had specific hypotheses regarding correlations with personality traits (e.g., the amygdala), parameter estimates of the effect size for each of the participants were extracted from the relevant activated cluster and were entered into correlation analyses with the scores on neuroticism, the total PPI score, and the coldheartedness score, using a standard statistical software package (SPSS, Version 13.0 [2004]). The other four NEO-FFI factors (extraversion, openness, agreeableness, and conscientiousness) and the other seven PPI scales (Machiavellian egocentricity, social potency, carefree nonplanfulness, fearlessness, blame externalization, impulsive nonconformity, and stress immunity) were entered into analysis as control variables. That is, we did not have hypotheses regarding these traits but included them as an estimate of the specificity of our results (i.e., predicting that significant correlations would not occur with any of these traits).

\section{Results and Discussion}

Results corresponding to the effects of moral and nonmoral picture viewing and emotion regulation, irrespective of individual variation in personality traits, have been reported in a previous study (Harenski \& Hamann, 2006).

Personality and mood scores. Neuroticism scores were transformed to $T$ scores, with the population mean defined as $T=50$ and one standard deviation of $T=10$. The mean sample score for neuroticism $(M=39.4, S D=$ 9.6 , range $=23.1-59.3$ ) was slightly lower than that for 
the average female college student population (although average when compared with that of adult female populations). Although there are no published norms for the PPI, but only for the PPI-R (Lilienfeld, personal communication, September 2007), the mean PPI and coldheartedness scores $(M=123, S D=13.2$, range $=100-140$, and $M=$ $12.7, S D=3.3$, range $=8-18$, respectively) were similar to those obtained by the first author in two subsequent female samples (total PPI, $M=113.1, S D=12.1$, and $M=$ 125.4, $S D=14.6$, respectively; coldheartedness, $M=$ $12.4, S D=3.5$, and $M=14.6, S D=2.8$, respectively; $N=14$ in each sample), as well as one male sample (total PPI, $M=122.3, S D=12.3$; coldheartedness, $M=13.9$, $S D=2.8 ; N=14)$.

Total PPI and coldheartedness scores were positively correlated $(r=.67, p=.024)$. No other significant correlations occurred between personality traits. Neuroticism and coldheartedness were negatively correlated $(r=-.38)$, in line with our predictions, but the correlation was not significant, likely owing to the small sample size. Negative mood state scores $(M=13.0, S D=3.3)$ were negatively correlated with coldheartedness scores $(r=-.59, p<$ .056). No other significant correlations occurred between personality traits and negative mood state.
Correlations between personality scores and brain activation during picture viewing. The effects of individual variation in neuroticism and psychopathic traits on brain activation during moral and nonmoral picture viewing were explored in the following contrasts: watch moral $>$ odd-even, watch nonmoral $>$ odd-even, watch moral $>$ watch nonmoral, and watch nonmoral $>$ watch moral. In the initial group random effects analysis, increased bilateral amygdala activity was observed in the watch moral $>$ odd-even contrast $(p<.003$ FWE small-volume corrected). Parameter estimates of left amygdala activity were positively correlated with neuroticism $[r(9)=.71, p=.02$; see Figure $1 \mathrm{~A}]$. When negative mood state scores were entered as a covariate, the correlation was reduced only slightly $(p=.063)$. The correlation with negative mood state while controlling for neuroticism was not significant $(p=.17)$. In contrast to the results for neuroticism, scores from the coldheartedness subscale of the PPI were negatively correlated with left-amygdala activity $[r(9)=-.658, p=.03$; see Figure 1B]. Amygdala activity also occurred at a reduced statistical threshold in the watch nonmoral $>$ odd-even contrast ( $p<.005$, uncorrected). Parameter estimates of right-amygdala activity were moderately negatively
A

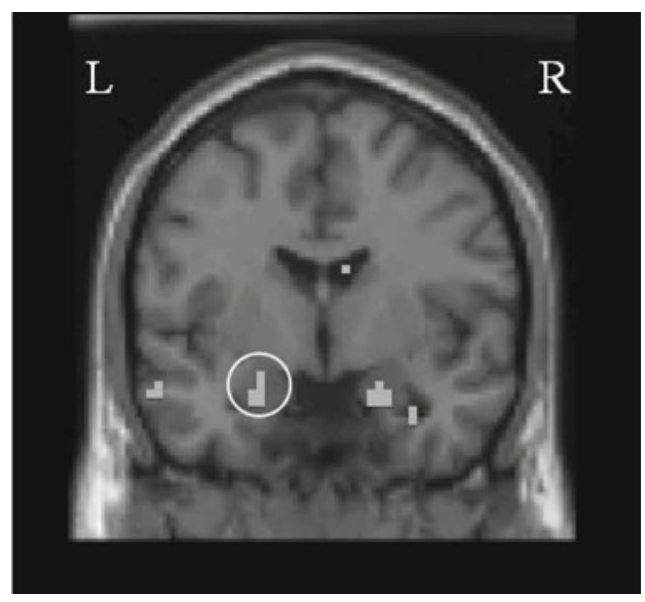

$x=-21, y=-6, z=-15$
B

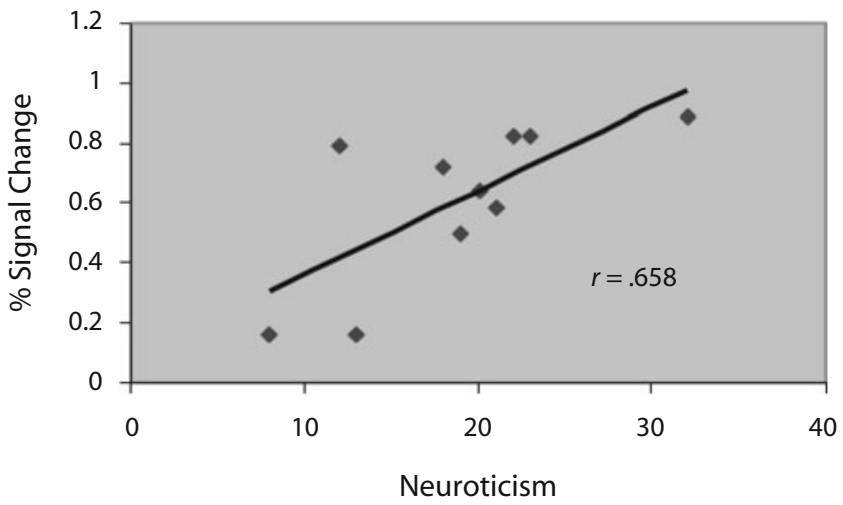

C

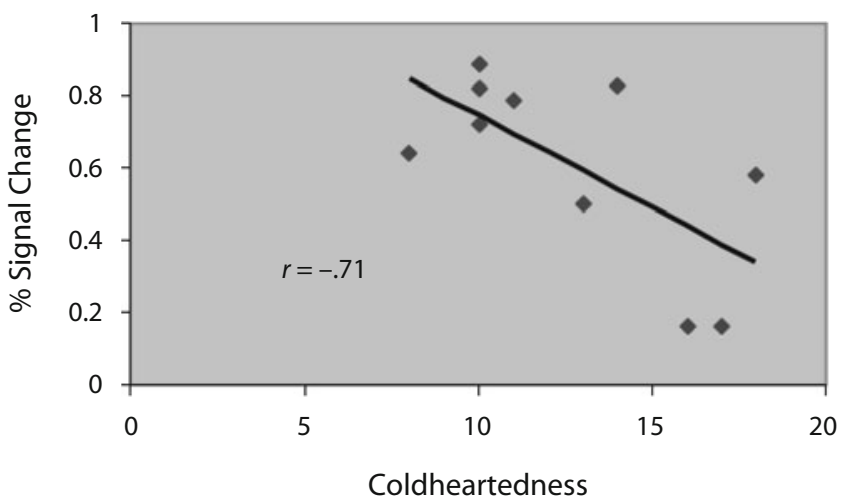

Figure 1. (A) Coronal slice showing bilateral amygdala activity in the watch moral $>$ odd-even contrast in Experiment 1 . (B) Positive correlation between neuroticism and parameter estimates of left-amygdala activity in the watch moral $>$ odd-even contrast. (C) Negative correlation between coldheartedness and parameter estimates of left-amygdala activity in the watch moral $>$ odd-even contrast. 
correlated with coldheartedness scores $[r(9)=-.541$, $p=.086]$ but were not significantly correlated with neuroticism.

We next explored whether total PPI or coldheartedness scores were correlated with neural activity that was greater in response to moral pictures, relative to nonmoral pictures. The watch moral $>$ watch nonmoral contrast revealed activity in the posterior cingulate (BA 31; $p=$ .052 , FWE small-volume corrected) and the posterior superior temporal sulcus (BA 39). Parameter estimates of activity in these regions were not significantly correlated with personality traits. Since we did not observe activity in other brain regions associated with moral processing in the watch moral > watch nonmoral contrast - notably, the MPFC - we investigated the possibility that activity in this region would be increased in response to moral stimuli only in participants scoring low on psychopathic traits. This would likely preclude finding a significant group effect at the $p<.001$ level. To investigate this hypothesis, total PPI and coldheartedness scores were entered into a whole-brain regression analysis as predictive factors in the watch moral $>$ watch nonmoral contrast. This analysis revealed a negative correlation between total PPI score and the anterior MPFC (BA 10;p< .005 , uncorrected; see Figure 2). No other regions were negatively correlated with total PPI score, and coldheartedness scores were not correlated with MPFC activity. When total PPI score was entered into the watch moral $>$ odd-even contrast, a negative correlation with MPFC activity (BA 10) was again found.

Correlations between personality scores and brain activation during emotion regulation. The effects of individual variation in neuroticism and psychopathic traits on brain activation during moral and nonmoral emotion regulation were explored in the following contrasts: decrease moral $>$ watch moral, watch moral $>$ decrease moral, decrease nonmoral $>$ watch nonmoral, and watch nonmoral $>$ decrease nonmoral. Unlike the results for moral and nonmoral picture viewing, we did not observe any significant correlations between personality traits and neural activity in ROIs that were specific to moral or nonmoral regulation conditions; thus, the following results are collapsed across moral and nonmoral conditions.

In the group random effects analysis, the watch $>$ decrease contrast revealed significant activation in one region, the insula. Activity in this region was not significantly correlated with any personality scores. The reverse contrast, decrease $>$ watch, revealed activity in the superior frontal cortex (BA 6; $p=.066$, FWE small-volume corrected; see Figure 3A). Parameter estimates of activity in this region were positively correlated with total PPI scores $[r(9)=.631, p=.037]$ and coldheartedness scores $[r(9)=.687, p=.02$; see Figures $3 \mathrm{~B}$ and $3 \mathrm{C}]$. Although we did not observe significant activity in other prefrontal regions, vlPFC activity did occur at a more lenient threshold ( $p<.01$, uncorrected). Parameter estimates of activity in this region were positively correlated with total PPI scores $[r(9)=.586, p=.058]$ and coldheartedness scores $[r(9)=.844, p=.001]$.
These results are in line with our prediction that psychopathic traits would be associated with increased superior and $\mathrm{vlPFC}$ activation during emotion regulation. However, our ability to explore correlations between personality traits and lateral prefrontal activity during regulation, particularly in the dlPFC, was limited due to a lack of activity in these regions. This may have been due to our study design. Unlike most prior emotion regulation studies, which used an event-related design, ours used a blocked design, which precluded the recording of responses to individual pictures. In one emotion regulation study that used a blocked design (Lévesque et al., 2003), vlPFC activity was observed only at a liberal threshold ( $p<.05$, uncorrected). Lack of lateral prefrontal activity during regulation has also been attributed to low power (Ochsner et al., 2004), which may have been a factor in the present experiment, given our use of only four blocks per condition. Another limitation of the present experiment is the fact that we did not obtain online emotion ratings in response to individual pictures and, thus, did not have an estimate of regulation success for our participants. We addressed these issues in Experiment 2. In addition, since the same participants as those in Experiment 1 completed Experiment 2, we were able to assess the within-participants replicability of our results across two different emotion regulation paradigms. Given our small sample size, this provides evidence against the possibility of Type I errors.

\section{EXPERIMENT 2}

Experiment 2 was conducted with the same participants as those who had participated in Experiment 1, immediately following the first experiment in the same fMRI scanning session. In contrast to Experiment 1, Experiment 2 utilized an event-related design in which each picture was presented individually and rated on emotional arousal following passive viewing or regulation. The difference between ratings of unpleasant pictures in the viewing and regulation conditions constituted an index of regulation success. We also investigated whether individual regulation success estimates were associated with personality traits and predictive of regulation-related neural activity.

\section{Method}

Stimuli and Design. Three sets of 16 unpleasant and one set of 16 neutral color pictures were selected from the IAPS (Lang et al., 1995). Three sets of 16 pleasant pictures were also included but were not the focus of the present experiment and will not be discussed further. No pictures were repeated from Experiment 1. Each set of unpleasant pictures was assigned to either the decrease or the watch condition. The assignment was counterbalanced across participants. An increase condition was also included, the results of which have been reported elsewhere (Kim \& Hamann, 2007). Neutral pictures were always assigned to the watch condition, since preliminary work indicated that participants found it confusing to decrease emotional reactions for stimuli that had little emotional content. An additional 24 unpleasant, 24 pleasant, and 8 neutral pictures were selected as distractor items for a memory task. The memory task was not the focus of the present experiment and will not be discussed further. 


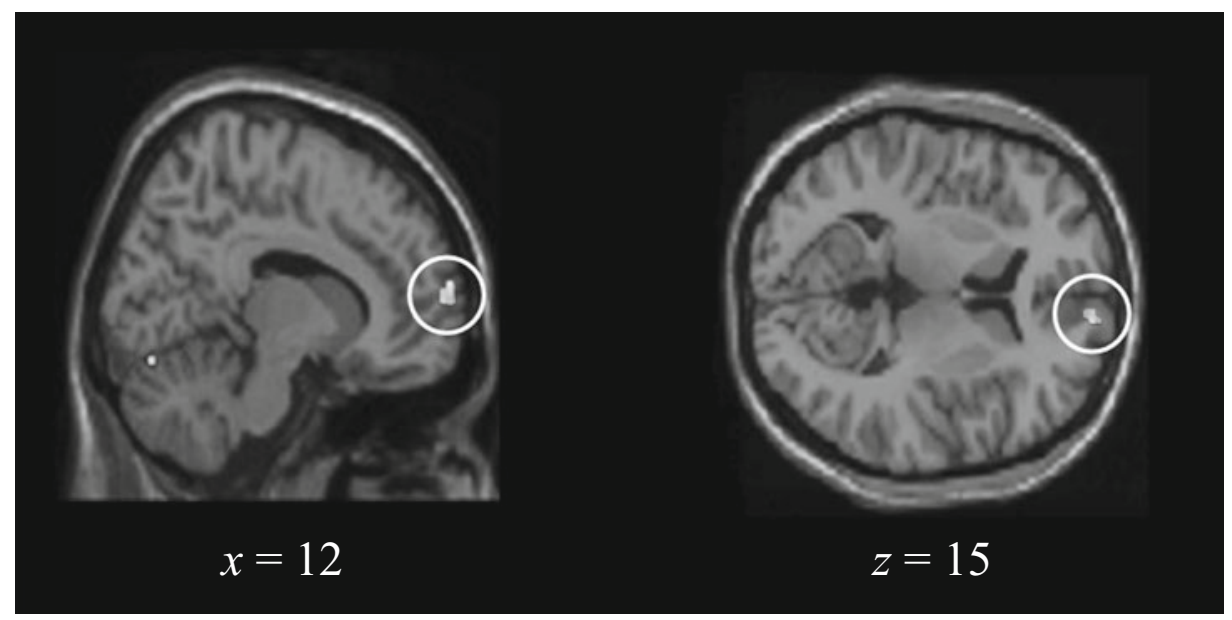

Figure 2. Negative correlation between the total Psychopathic Personality Inventory score and medial prefrontal cortex (BA 10) activation in the watch moral > watch nonmoral contrast, as revealed by whole-brain regression analyses in Experiment 1.

A

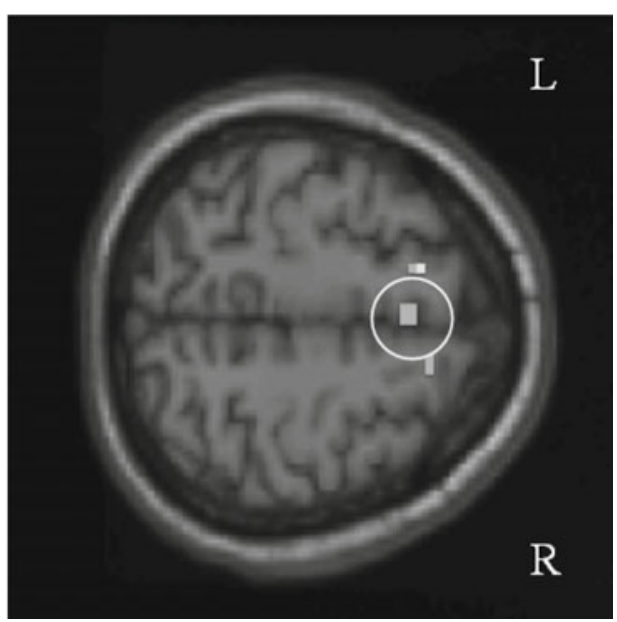

$x=0, y=15, z=54$
B

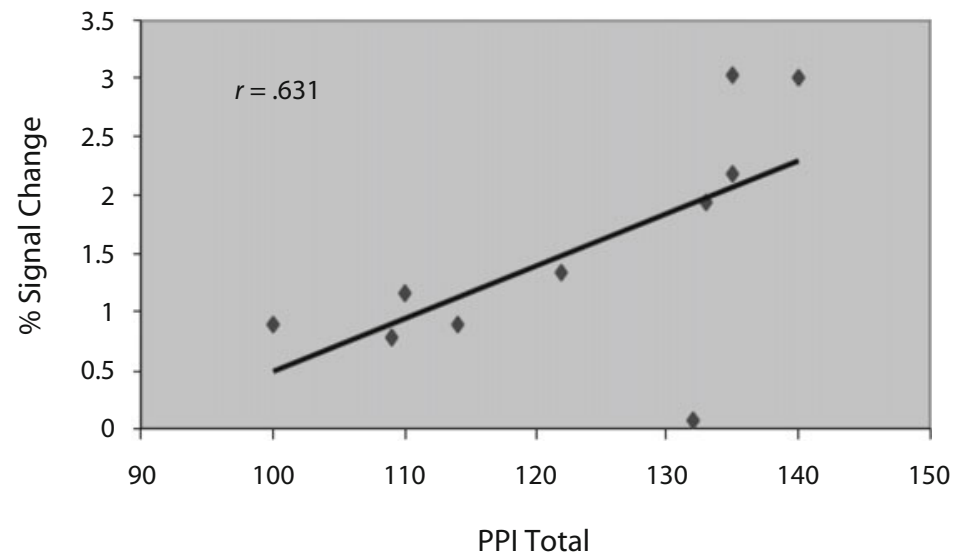

C

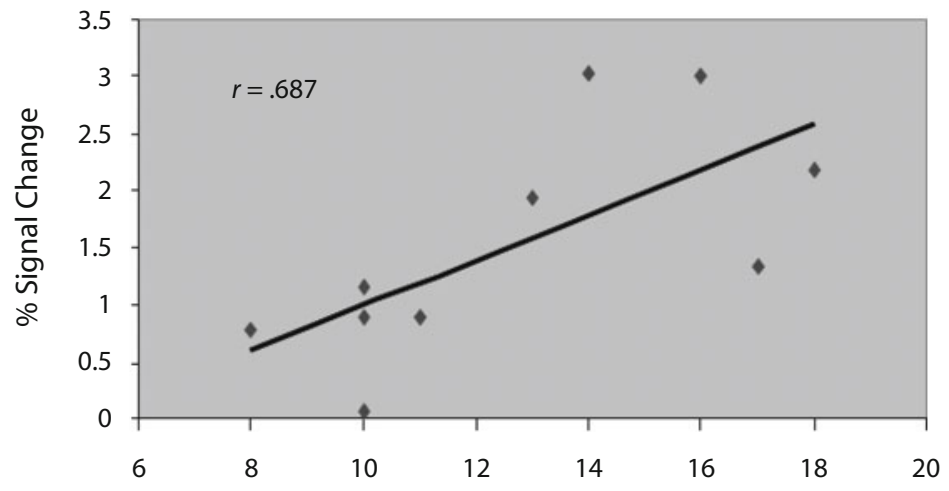

Coldheartedness

Figure 3. (A) Axial slice showing superior frontal activity (BA 6) in the decrease $>$ watch contrast in Experiment 1. (B) Positive correlation between total Psychopathic Personality Inventory (PPI) score and parameter estimates of superior frontal activity in the decrease $>$ watch contrast. (C) Positive correlation between coldheartedness and parameter estimates of superior frontal activity in the decrease $>$ watch contrast. 
A

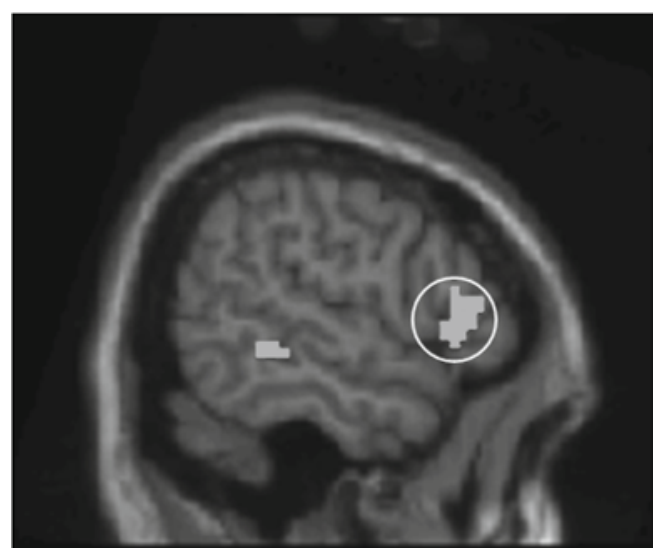

$x=57, y=27, z=9$
B
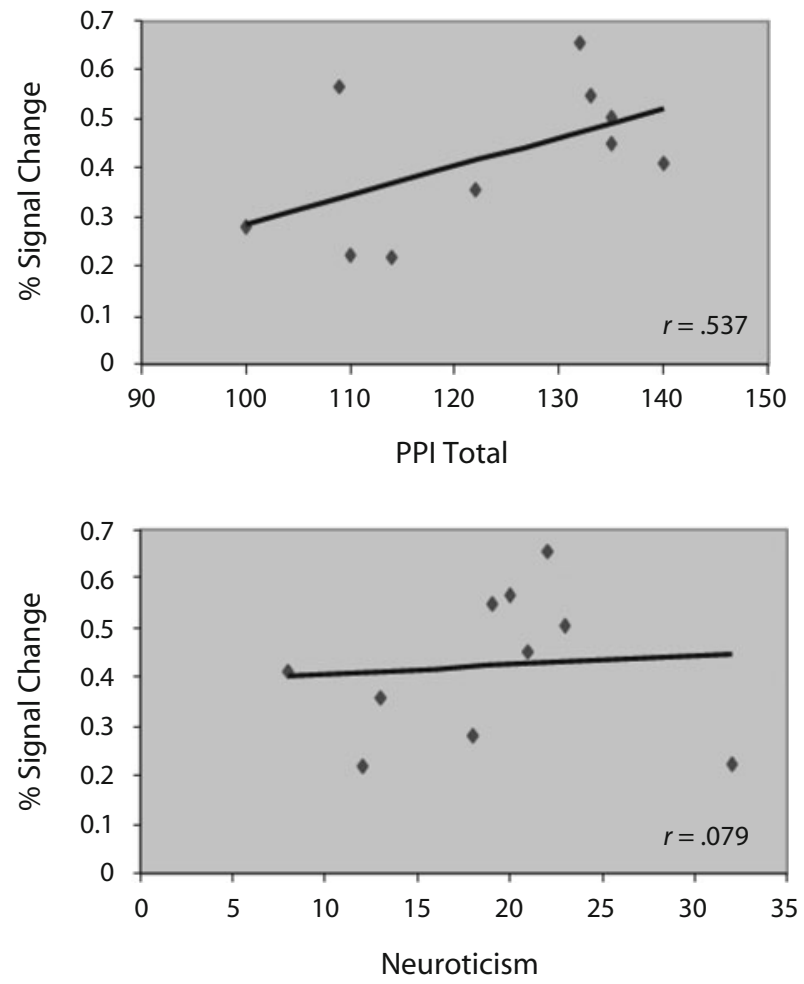

D
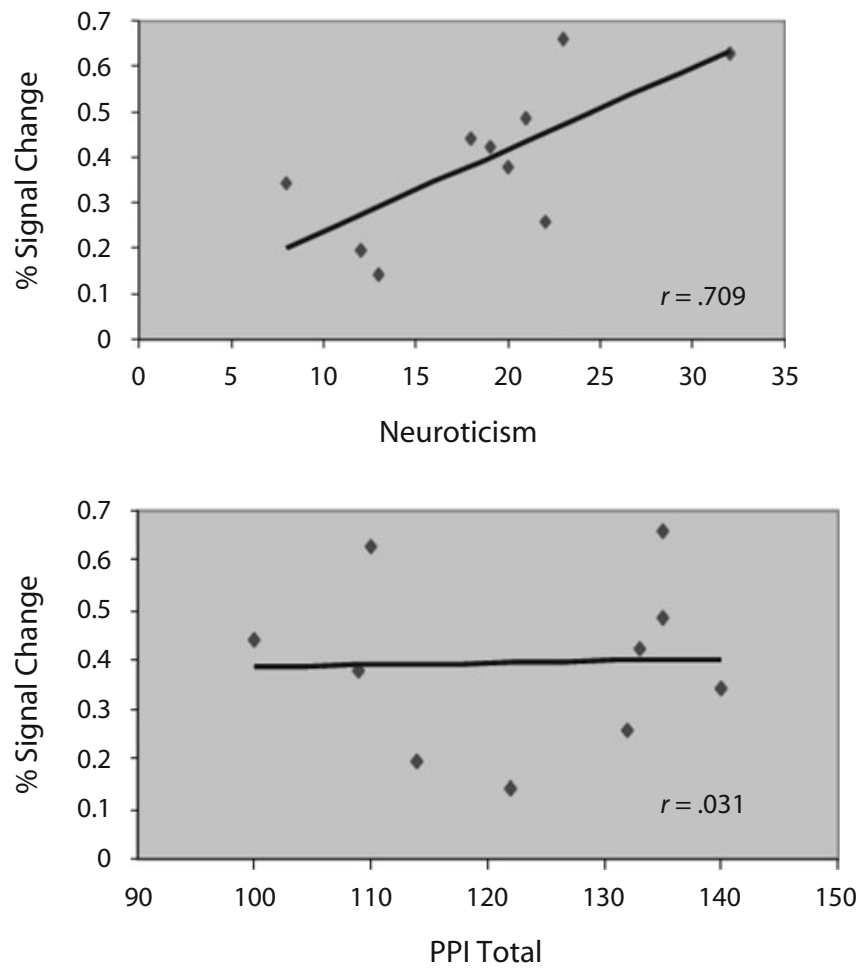

Figure 4. (A) Sagittal slice showing ventrolateral prefrontal cortex (vIPFC) activity (BA 45) in the decrease $>$ watch contrast in Experiment 2. (B) Positive correlation between total Psychopathic Personality Inventory (PPI) score, but not neuroticism, and parameter estimates of vIPFC activity in the decrease $>$ watch contrast. (C) Sagittal slice showing dorsolateral prefrontal cortex (dIPFC) activity (BA 9) in the decrease > watch contrast in Experiment 2. (D) Positive correlation between neuroticism, but not total PPI score, and parameter estimates of dIPFC activity in the decrease $>$ watch contrast. 
Procedure. The regulation instructions given to participants and the prescanning practice task were the same as those in Experiment 1. Each trial proceeded as follows. First, an instruction in white letters appeared in the center of a black screen for $2 \mathrm{sec}$. The instruction was either WATCH or DECREASE, indicating how the participants should evaluate the following picture. The picture was displayed for $8 \mathrm{sec}$, during which the participants either viewed the picture and allowed themselves to experience any emotions the picture evoked or attempted to decrease their emotional response. Following the picture, a rating scale was displayed that asked the participants to rate the strength of the emotion they were currently feeling on a scale of 1 (weak) to 4 (strong) by pressing a button on a four-button fiber-optic response pad. Next, a fixation cross was presented for $2 \mathrm{sec}$ prior to the start of the next trial. A total of 48 trials (16 watch negative, 16 decrease negative, and 16 watch neutral) occurred over four runs. The conditions were presented in a pseudorandom order in each run, so that no more than two identical regulation conditions were presented consecutively. As in Experiment 1, images were rear-projected using an LCD projector, controlled by a laptop computer. Tasks were designed and presented using Presentation software (Version .50; Neurobehavioral Systems, 2002, http://nbs .neuro-bs.com).

Personality measures. The same personality measures as those described in Experiment 1 were used in data analysis.

MRI data acquisition and analysis. MRI data acquisition parameters and analysis strategies were primarily the same as those described in Experiment 1, except that scanning consisted of four runs, with a total of 185 scans in each run. Condition effects were modeled using a boxcar regressor convolved with a canonical hemodynamic response function for the duration of each picture presentation $(8 \mathrm{sec})$, as opposed to being modeled across the entire 20 -sec picture block, as in Experiment 1. Also, since Experiment 2 did not involve moral or odd-even conditions, the primary contrasts of interest were watch negative $>$ watch neutral and decrease negative $>$ watch negative. Accordingly, only ROIs associated with emotion regulation were defined and utilized in data analysis. Finally, since we had directional hypotheses for associations between personality traits and neural activity during picture viewing and regulation, the majority of which were confirmed in Experiment 1, one-tailed tests will be reported for correlations between neuroticism, coldheartedness, and amygdala activity during picture viewing and between total PPI score, coldheartedness, and superior frontal and vlPFC activity during regulation.

\section{Results and Discussion}

Results corresponding to the effects of unpleasant picture viewing and emotion regulation, irrespective of individual variation in personality traits, have been reported in a previous study (Kim \& Hamann, 2007).

Success in decreasing emotional responses. A paired samples $t$ test comparing online arousal ratings for negative pictures in the decrease versus the watch condition was significant $[t(9)=5.36, p<.0001]$, indicating that the participants reported experiencing less emotional arousal when down-regulating emotion (watch, $M=2.84, S D=$ 0.54 ; decrease, $M=2.24, S D=0.42$ ). This decrease in rated arousal associated with down-regulation indicates that the participants were successful in decreasing their emotional responses. Regulation success (mean arousal ratings in decrease vs. watch condition) was positively correlated with both total PPI and coldheartedness scores, but the correlations were not significant $[r(9)=.22, p=.51$; $r(9)=.32, p=.34$, respectively], likely owing to the small sample size. Regulation success was not significantly correlated with neuroticism scores $[r(9)=-.04, p=.91]$.
Correlations between personality scores and brain activation during picture viewing. Effects of individual variation in neuroticism and psychopathic traits on amygdala activity during unpleasant picture viewing were explored in the watch negative $>$ watch neutral contrast. Although amygdala activity was not observed at the $p<.001$ level, left-amygdala activity occurred at a reduced threshold ( $p<.01$, uncorrected). Parameter estimates of activity in this region were positively correlated with neuroticism $[r(9)=.539, p=.044]$. When negative mood state scores were entered as a covariate, the correlation was reduced only slightly $(p=.047)$. The correlation between negative mood state and leftamygdala activity while controlling for neuroticism was not significant $(p=.42)$. A negative correlation occurred between left-amygdala activity and coldheartedness, but the correlation fell short of significance $[r(9)=-.39$, $p=.12]$. Overall, these findings are in line with the results of Experiment 1.

Correlations between personality scores and brain activation during emotion regulation. The effects of individual variation in neuroticism and psychopathic traits on brain activation during emotion regulation were explored in the decrease negative $>$ watch negative contrast. In the group random effects analysis, this contrast revealed activity in several prefrontal regions, including the superior frontal cortex (BA 6; $p=.001$, FWE smallvolume corrected), the bilateral vlPFC [BA 45, $p=.10$ (left), $p=.001$ (right) FWE small-volume corrected; BA 47, $p=.001$ (left), $p=.003$ (right), FWE smallvolume corrected; see Figure 4A], and the bilateral dlPFC [BA 9; $p=.001$ (left), $p=.003$ (right), FWE smallvolume corrected; see Figure 4C]. Parameter estimates of superior frontal activity were positively correlated with total PPI scores $[r(9)=.541, p=.043]$ and coldheartedness scores $[r(9)=.489, p=.063]$. Neuroticism was not significantly correlated with superior frontal activity $[r(9)=-.156, p=.65]$. These results are in line with the findings of Experiment 1.

Parameter estimates of right-vlPFC activity (BA 45) were positively correlated with total PPI score $[r(9)=$ $.537, p=.045]$, but not with neuroticism $[r(9)=.079$, $p=.817]$ or coldheartedness $[r(9)=-.015, p=.965$; see Figure 4B]. In contrast, parameter estimates of rightdIPFC activity (BA 9) were positively correlated with neuroticism $(r=.709, p=.015)$, but not with total PPI score $[r(9)=.031, p=.928]$ or coldheartedness $[r(9)=$ $-.075, p=.827$; see Figure 4D]. When negative mood state scores were entered as a covariate for neuroticism, the correlation was reduced only slightly $(p=.054)$. The correlation with negative mood state controlling for neuroticism was not significant ( $p=.97)$.

In summary, the results of Experiment 2 replicated the positive correlation between neuroticism and leftamygdala activity during the viewing of unpleasant pictures and the positive correlations between psychopathic traits and superior prefrontal and right-vlPFC activity during regulation that occurred in Experiment 1. We also observed a double dissociation finding in Experiment 2 
in which total PPI score, but not neuroticism, was positively correlated with right-vlPFC activity during emotion regulation, whereas neuroticism, but not total PPI score, was positively correlated with right-dlPFC activity during emotion regulation. None of the correlations reported in Experiment 1 or 2 occurred with any of the other NEO-FFI personality scores (extraversion, openness, agreeableness, conscientiousness) or with any of the other PPI subscales (Machiavellian egocentricity, social potency, carefree nonplanfulness, fearlessness, blame externalization, impulsive nonconformity, stress immunity).

\section{GENERAL DISCUSSION}

Neuroticism is associated with increased negative affect and, possibly, a diminished capacity to downregulate negative emotional experiences. Psychopathy, in contrast, is associated with reduced emotional responses to negative emotional stimuli. In the present study, we examined the effects of neuroticism and psychopathic traits on the neural correlates of viewing and decreasing responses to unpleasant pictures. We predicted that neuroticism would be positively correlated with emotionrelated brain activity, whereas the reverse was predicted for psychopathic traits. We predicted that individuals scoring high in neuroticism would show increased prefrontal activity associated with effortful regulation, whereas individuals scoring high in psychopathic traits were expected to show increased prefrontal activity associated with successful regulation. We also compared responses to unpleasant pictures that did or did not contain moral violations and predicted that neural responses to moral stimuli would be predicted by degree of psychopathic traits across individuals.

\section{Correlations Between Neuroticism and Psychopathic Traits and Neural Activity During Passive Viewing of Unpleasant Pictures}

When participants viewed unpleasant pictures depicting moral violations in Experiment 1, amygdala activity in individual participants was positively correlated with neuroticism scores. This result is consistent with our hypothesis that neuroticism would be positively correlated with amygdala activity during unpleasant picture viewing, although the specificity of this result to the moral condition was unexpected. A positive correlation between neuroticism and amygdala activity during unpleasant picture viewing also occurred in Experiment 2. Importantly, amygdala activity was not significantly correlated with other NEO scales, such as extraversion, emphasizing the specificity of the result to neuroticism. In addition, the results were not due to secondary effects of negative mood state associated with neuroticism. Overall, the positive correlation between neuroticism and amygdala activity during unpleasant picture viewing is consistent with our expectation that individuals higher in neuroticism would show increased activity in brain regions involved in emotional processing.
In contrast to the results for neuroticism, amygdala activity that occurred during unpleasant picture viewing in Experiment 1 was negatively correlated with scores on the coldheartedness subscale of the PPI. This result is consistent with our predictions and suggests that individuals high in coldheartedness had reduced emotional responses to unpleasant pictures. A negative correlation between coldheartedness and amygdala activity during unpleasant picture viewing also occurred in Experiment 2, although the result fell short of significance. We did not observe similar correlations with the total PPI score, indicating that this association is particularly related to the low-emotional-reactivity dimension of psychopathy. This result is consistent with previous findings of reduced amygdala activity during emotion processing in psychopathy (Birbaumer et al., 2005; Kiehl et al., 2001), and the specificity of the result to the coldheartedness subscale suggests that reduced amygdala activity might be particularly associated with the affective component of psychopathy, as opposed to other components, such as antisocial behavior.

\section{Effects of Neuroticism and Psychopathic Traits on Neural Activity During Voluntary Emotion Regulation to Unpleasant Pictures}

When participants regulated their emotional responses to unpleasant pictures in Experiment 1, increased activity occurred in the superior frontal cortex (BA 6). Activity in this region was positively correlated with total PPI and coldheartedness scores. Both of these results were replicated in Experiment 2. Although the superior frontal cortex is one of the most consistently activated regions in studies of emotion regulation (Ochsner \& Gross, 2005), its role in emotion regulation is not clear. Across studies, the coordinates of observed activations tend to center in the supplementary motor region, a region that has been implicated in internally generated actions (Passingham, 1987) or, more specifically, preparation for action (Brett, Jenkins, Stein, \& Brooks, 1997). Activation of this region in the present study may represent the recruitment of cognitive resources to be utilized in regulating emotional responses and/or the selection of a reinterpretive framework with which to decrease emotional reactions to a specific unpleasant stimulus. These processes might have been more readily recruited by individuals scoring high in psychopathic traits.

In Experiments 1 and 2, we also found a positive correlation between PPI scores and right-vlPFC activity when the participants were decreasing emotional responses to unpleasant pictures. This finding provides further support for our prediction that psychopathic traits would be associated with increased prefrontal activity during emotion regulation. Another interpretation of the positive correlations between psychopathic traits and regulation-related prefrontal activity is that this pattern represents a compensatory mechanism, recruited in response to limited input from limbic regions such as the amygdala. This interpretation is consistent with previous characterizations of neural dysfunction in psychopathy (Kiehl, 2006; Kiehl et al., 2001) and 
is also consistent with our finding of a negative correlation between coldheartedness and amygdala activation during unpleasant picture viewing. The association between psychopathic traits, particularly the low-emotional-reactivity component, and increased prefrontal activation might become particularly salient during emotion regulation when the individual is specifically attending to their emotional responses in an effort to diminish them. In individuals high in psychopathic traits, this input is likely reduced, leading to a compensatory increase in prefrontal activation.

In contrast to the positive correlation between psychopathic traits and superior and vlPFC activity, we found a positive correlation between neuroticism and rightdlPFC activity when the participants decreased emotional responses to unpleasant pictures, as was expected. This result is consistent with that of a previous study by Canli et al. (2001), who reported a positive correlation between neuroticism and dlPFC activity during an emotional picture viewing task. It is also consistent with the results of prior research implicating this region in effortful regulation, where activity increases with task difficulty (Lévesque et al., 2003). Decreasing negative emotions is indeed considered to be a difficult task, as has been shown by prior research comparing up- and down-regulation of emotional responses (Kim \& Hamann, 2007; Ochsner et al., 2004). Subjective reports from the participants in these studies indicated that they found down-regulation to be a more difficult task than up-regulation. A recent study reported a negative correlation between dlPFC activity during regulation and postscan ratings of regulation success (Eippert et al., 2007). Taken together, these results suggest that individuals scoring high on neuroticism had more difficulty decreasing emotional responses. However, it is important to note that we did not observe a negative correlation between neuroticism and our behavioral measure of regulation success. Although this may be due to demand characteristics (i.e., participants having difficulty regulating emotional responses may have still felt the need to demonstrate successful task performance), we interpret this result tentatively, pending future replication.

As was mentioned earlier, the primary regulation strategy utilized by our participants was a reappraisal strategy in which the scenes were interpreted as being unreal (e.g., from a movie). However, individuals may choose different regulation strategies to decrease negative emotions, such as reappraisal versus suppression, the latter of which has typically been associated with less regulation success (Gross, 1998). Individual differences in personality traits such as neuroticism and psychopathic traits may differentially predict the use of specific regulation strategies, which may result in the recruitment of different neural systems. This is an important area for future research.

\section{Psychopathic Traits and Reduced MPFC Activity During Moral Processing}

We were interested in exploring the association between psychopathic traits and neural activity during moral versus nonmoral picture viewing and regulation in Experiment 1. In contrast to the results for coldheartedness, which were generally consistent across moral and nonmoral picture viewing conditions, total PPI scores were negatively correlated with anterior MPFC (BA 10) activation in the moral picture viewing condition only. There are two aspects of this finding that are worth noting. First, the correlation was found in the moral $>$ nonmoral contrast, highlighting the specificity of the association to pictures that depicted moral violations. Since the moral and nonmoral pictures were matched on emotional arousal, the specificity of this result to the moral condition indicates that the association is not merely due to a decrease in affective reactivity in individuals high on psychopathic traits. Instead, it suggests that the association is specifically related to the moral content of the stimuli. Second, the correlation was specific to the MPFC region; no other regions were correlated with PPI score in the moral condition. Abnormal structure and function of the prefrontal cortex has been found in individuals diagnosed with psychopathy or antisocial personality disorder (Kiehl et al., 2001; Lapierre, Braun, \& Hodgins, 1995; Raine, Lencz, Bihrle, LaCasse, $\&$ Colletti, 2000; Yang et al., 2005). In addition, a recent study showed that patients with MPFC damage did not integrate emotional aspects of moral dilemmas into decisions regarding the appropriate outcome of the dilemmas to the same extent as patients with damage to other brain regions or individuals without brain damage (Koenigs et al., 2007). The reduced MPFC activity we observed in response to viewing moral pictures in individuals high in psychopathic traits suggests that these individuals are particularly less responsive to emotional aspects of moral violations, which may diminish their ability to reason about moral situations.

A limitation regarding the correlations between psychopathic traits and neural activity during both emotion regulation and moral picture viewing conditions is that all of our participants were female. Since psychopathy occurs more often in males and may manifest somewhat differently in females (Cale \& Lilienfeld, 2002), caution should be taken in generalizing these findings to self-reported psychopathic traits in males. However, some evidence suggests that gender differences in the expression of psychopathy may be found primarily in the aggression/impulsivity domains, as opposed to the affective domain (see Verona \& Vitale, 2006), the latter of which likely has the strongest impact on emotion regulation processes, as well as responses to moral violations. Overall, little information is available regarding differential expression of psychopathy in males and females, and more research in this area is needed. The present findings provide a starting point for investigating associations between psychopathic traits and neural correlates of emotional-moral processing and how these might differ in males and females.

\section{Summary and Conclusions}

This is the first study, to our knowledge, to explore the neural correlates of neuroticism and psychopathic traits in the context of emotion regulation. We observed a positive correlation between neuroticism and amygdala activity during the viewing of unpleasant pictures, 
and a negative correlation between coldheartedness and amygdala activity in the same condition. During emotion regulation, we observed positive correlations between psychopathic traits, but not neuroticism, and superior and vlPFC activity. In contrast, we observed a positive correlation between neuroticism, but not psychopathic traits, and dlPFC activity during regulation. In addition, we found a negative correlation between psychopathic traits and MPFC activity that was specific to processing moral violations. Given the small sample size of the present study, these results should be considered preliminary, pending replication in larger samples. Overall, the results indicate that patterns of brain activation during the processing of negative emotional stimuli and during emotion regulation depend on the degree to which individuals exhibit particular personality traits. Because individual differences in personality and other domains (e.g., gender) have previously been associated with neural responses to emotional stimuli (for a review, see Hamann \& Canli, 2004), it will be important to build upon existing knowledge of individual differences in the neural correlates of emotion processing and to further explore potential individual differences in the neural correlates of emotion regulation.

\section{AUTHOR NOTE}

Correspondence concerning this article should be addressed to C. L. Harenski, The MIND Research Network, 1101 Yale Blvd. NE, Albuquerque, NM 87131 (e-mail: charenski@mrn.org).

\section{REFERENCES}

Anderson, S. W., Bechara, A., Damasio, H., Tranel, D., \& Damasio, A. R. (1999). Impairment of social and moral behavior related to early damage in human prefrontal cortex. Nature Neuroscience, 2, 10321037. doi: $10.1038 / 14833$

Aniskiewicz, A. S. (1979). Autonomic components of vicarious conditioning and psychopathy. Journal of Clinical Psychology, 35, 60-67. doi:10.1002/1097-4679(197901)35:1<60::AID -JCLP2270350106>3.0.CO;2-R

Baumeister, R. F., \& ExLIne, J. J. (2000). Self-control, morality, and human strength. Journal of Social \& Clinical Psychology, 19, 29-42.

Bienvenu, O. J., \& Stein, M. B. (2003). Personality and anxiety disorders: A review. Journal of Personality Disorders, 17, 139-151. doi:10.1521/pedi.17.2.139.23991

Birbaumer, N., Veit, R., Lotze, M., Erb, M., Hermann, C., Grodd, W., \& FLOR, H. (2005). Deficient fear conditioning in psychopathy: A functional magnetic resonance imaging study. Archives of General Psychiatry, 62, 799-805. doi:10.1001/archpsyc.62.7.799

BLAIR, R. J. R. (1997). Moral reasoning in the child with psychopathic tendencies. Personality \& Individual Differences, 26, 477-485. doi:10.1016/S0191-8869(96)00249-8

BLAIR, R. J. R. (1999). Responsiveness to distress cues in the child with psychopathic tendencies. Personality \& Individual Differences, 27, 135-145. doi:10.1016/S0191-8869(98)00231-1

Blair, R. J. R., Jones, L., Clark, F., \& Smith, M. (1995). Is the psychopath "morally insane"? Personality \& Individual Differences, 19, 741-752. doi:10.1016/0191-8869(95)00087-M

Blair, R. J. R., Jones, L., Clark, F., \& Smith, M. (1997). The psychopathic individual: A lack of responsiveness to distress cues? Psychophysiology, 34, 192-198.

Blair, R. J. R., Mitchell, D. [G. V.], \& Blair, K. (2005). The psychopath: Emotion and the brain. Oxford: Blackwell.

Blair, R. J. R., Mitchell, D. G. V., Peschardt, K. S., Colledge, E., Leonard, R. A., Shine, J. H., ET AL. (2004). Reduced sensitiv- ity to others' fearful expressions in psychopathic individuals. Personality \& Individual Differences, 37, 1111-1122. doi:10.1016/j .paid.2003.10.008

Blair, R. J. R., Mitchell, D. G. V., \& Richell, R. A. (2002). Turning a deaf ear to fear: Impaired recognition of vocal affect in psychopathic individuals. Journal of Abnormal Psychology, 111, 682-686.

Blair, R. J. R., Sellars, C., Strickland, I., \& Clark, F. (1995). Emotion attributions in the psychopath. Personality \& Individual Differences, 19, 431-437. doi:10.1016/0191-8869(95)00080-P

Brett, M., Jenkins, I. H., Stein, J. F., \& Brooks, D. J. (1997). Movement selection without preparation does not activate the SMA. NeuroImage, 5, S296.

CAle, E., \& Lilienfeld, S. O. (2002). Histrionic personality disorder and antisocial personality disorder: Sex differentiated manifestations of psychopathy? Journal of Personality Disorders, 16, 52-72. doi:10.1521/pedi.16.1.52.22557

CANLI, T., \& Amin, Z. (2002). Neuroimaging of emotion and personality: Scientific evidence and ethical considerations. Brain \& Cognition, 50, 414-431. doi:10.1016/S0278-2626(02)00517-1

Canli, T., Amin, Z., HaAs, B., Omura, K., \& Constable, R. T. (2004). A double dissociation between mood states and personality traits in the anterior cingulate. Behavioral Neuroscience, 118, 897-904. doi:10.1037/0735-7044.118.5.897

Canli, T., Zhao, Z., Desmond, J. E., Kang, E., Gross, J., \& Gabrieli, J. D. E. (2001). An fMRI study of personality influences on brain reactivity to emotional stimuli. Behavioral Neuroscience, 115, 33-42. doi:10.1037/0735-7044.115.1.33

Costa, P. T., \& McCrae, R. R. (1980). Influence of extraversion and neuroticism on participantive well-being: Happy and unhappy people. Journal of Personality \& Social Psychology, 38, 668-678. doi:10.1037/0022-3514.38.4.668

Costa, P. T., \& McCrae, R. R. (1992). Revised NEO Personality Inventory (NEO-PI-R) and NEO Five-Factor Inventory (NEO-FFI): Professional manual. Odessa, FL: Psychological Assessment Resources.

Davidson, J., Miller, R., \& Strickland, R. (1985). Neuroticism and personality disorder in depression. Journal of Affective Disorders, $\mathbf{8}$, 177-182. doi:10.1016/0165-0327(85)90042-4

Eippert, F., Veit, R., Weiskopf, N., Erb, M., Birbaumer, N., \& ANDERS, S. (2007). Regulation of emotional responses elicited by threatrelated stimuli. Human Brain Mapping, 28, 409-423. doi:10.1002/ hbm. 20291

Eisenberger, N. I., Lieberman, M. D., \& Satpute, A. B. (2005). Personality from a controlled processing perspective: An fMRI study of neuroticism, extraversion, and self-consciousness. Cognitive, Affective, \& Behavioral Neuroscience, 5, 169-181.

EysencK, H. J. (1990). Biological dimensions of personality. In L. A. Pervin (Ed.), Handbook of personality: Theory and research (pp. 244276). New York: Guilford.

Friston, K. J., Jezzard, P., \& Turner, R. (1994). Analysis of functional MRI time-series. Human Brain Mapping, 1, 153-171.

Garavan, H., Pendergrass, J. C., Ross, T. J., Stein, E. A., \& Risinger, R. C. (2001). Amygdala response to both positively and negatively valenced stimuli. NeuroReport, 12, 2779-2783. doi:10.1097/00001756 $-200108280-00036$

Garnefski, N., Kraaij, V., \& Spinhoven, P. (2001). Negative life events, cognitive emotion regulation and emotional problems. Personality \& Individual Differences, 30, 1311-1327. doi:10.1016/S0191 -8869(00)00113-6

Gordon, H. L., BAIRD, A. A., \& END, A. (2004). Functional differences among those high and low on a trait measure of psychopathy. Biological Psychiatry, 56, 516-521. doi:10.1016/j.biopsych.2004.06.030

GraY, J. A. (1972). The psychophysiological basis of introversionextraversion: A modification of Eysenck's theory. In V. D. Nebylitsyn \& J. A. Gray (Eds.), Biological bases of individual behavior (pp. 182205). New York: Academic Press.

GreENE, J., \& HAIDT, J. (2002). How (and where) does moral judgment work? Trends in Cognitive Sciences, 6, 517-523.

Greene, J. D., Nystrom, L. E., Engell, A. D., Darley, J. M., \& CoHEn, J. D. (2004). The neural bases of cognitive conflict and control in moral judgment. Neuron, 44, 389-400.

Greene, J. D., Sommerville, R. B., Nystrom, L. E., Darley, J. M., 
\& Cohen, J. D. (2001). An fMRI investigation of emotional engagement in moral judgment. Science, 293, 2105-2108. doi:10.1126/ science. 1062872

Gross, J. J. (1998). Antecedent- and response-focused emotion regulation: Divergent consequences for experience, expression, and physiology. Journal of Personality \& Social Psychology, 74, 224-237. doi:10.1037/0022-3514.74.1.224

Gross, J. J., \& John, O. P. (2003). Individual differences in two emotion regulation processes: Implications for affect, relationships, and well-being. Journal of Personality \& Social Psychology, 85, 348-362. doi:10.1037/0022-3514.85.2.348

Gross, J. J., \& Munoz, R. F. (1995). Emotion regulation and mental health. Clinical Psychology: Science \& Practice, 2, 151-164.

HAIDT, J. (2001). The emotional dog and its rational tail: A social intuitionist approach to moral judgment. Psychological Review, 108, 814-834. doi:10.1037/0033-295X.108.4.814

Hamann, S. [B.], \& Canli, T. (2004). Individual differences in emotion processing. Current Opinion in Neurobiology, 14, 233-238. doi:10.1016/j.conb.2004.03.010

Hamann, S. B., Ely, T. D., Hoffman, J. M., \& Kilts, C. D. (2002). Ecstasy and agony: Activation of human amygdala in positive and negative emotion. Psychological Science, 13, 135-141. doi:10.1111/1467 $-9280.00425$

Hamann, S. [B.], \& MaO, H. (2002). Positive and negative emotional verbal stimuli elicit activity in the left amygdala. NeuroReport, 13, 15-19. doi:10.1097/00001756-200201210-00008

Hare, R. D. (1998). Psychopaths and their nature: Implications for the mental health and criminal justice systems. In T. Millon, E. Simonsen, M. Biket-Smith, \& R. D. Davis (Eds.), Psychopathy: Antisocial, criminal and violent behavior. New York: Guilford.

HARENSKi, C. L., \& HAMANN, S. (2006). Neural correlates of regulating emotions related to moral violations. NeuroImage, 30, 313-324.

Heekeren, H. R., Wartenburger, I., Schmidt, H., Prehn, K., Schwintowski, H. P., \& Villringer, A. (2005). Influence of bodily harm on neural correlates of semantic and moral decision making. NeuroImage, 24, 887-897.

Heekeren, H. R., Wartenburger, I., Schmidt, H., Schwintowski, H. P., \& Villringer, A. (2003). An fMRI study of simple ethical decision-making. NeuroReport, 14, 1215-1219. doi:10.1097/00001756 -200307010-00005

Herwig, U., Baumgartner, T., Kaffenberger, T., BrüHl, A., KottLOW, M., Schreiter-Gasser, U., ET AL. (2007). Modulation of anticipatory emotion and perception processing by cognitive control. NeuroImage, 37, 652-662.

Holmes, A. P., \& Friston, K. J. (1998). Generalisability, random effects, and population inference. NeuroImage, 7, S754.

Holmes, A. P., Josephs, O., Büchel, C., \& Friston, K. J. (1997). Statistical modelling of low frequency confounds in fMRI. NeuroImage, 5, S480.

Isenberg, N., Silbersweig, D., Engelien, A., Emmerich, S., MalaVADE, K., Beattie, B. C., ET AL. (1999). Linguistic threat activates the human amygdala. Proceedings of the National Academy of Sciences, 96, 10456-10459.

KIEHL, K. A. (2006). A cognitive neuroscience perspective on psychopathy: Evidence for paralimbic system dysfunction. Psychiatry Research, 142, 107-128. doi:10.1016/j.psychres.2005.09.013

Kiehl, K. A., Smith, A. M., Hare, R. D., MendreK, A., Forster, B. B., BRINK, J., \& LidDLE, P. F. (2001). Limbic abnormalities in affective processing by criminal psychopaths as revealed by functional magnetic resonance imaging. Biological Psychiatry, 50, 677-684. doi:10.1016/S0006-3223(01)01222-7

Kim, S., \& Hamann, S. (2007). Neural correlates of positive and negative emotion regulation. Journal of Cognitive Neuroscience, 19, 776798. doi:10.1162/jocn.2007.19.5.776

Koenigs, M., Young, L., Adolphs, R., Tranel, D., Cushman, F. Hauser, M., \& Damasio, A. (2007). Damage to the prefrontal cortex increases utilitarian moral judgments. Nature, 446, 908-911. doi:10.1038/nature 05631

KoKkonen, M., \& PUlKkinen, L. (2001). Extraversion and neuroticism as antecedents of emotion regulation and dysregulation in adulthood. European Journal of Personality, 15, 407-424. doi:10.1002/per.425

LANG, P. J., Bradley, M. M., \& CUthbert, B. N. (1995). International
Affective Picture System (IAPS). Bethesda, MD: National Institute of Mental Health Center for the Study of Emotion and Attention.

Lapierre, D., Braun, C. M. J., \& Hodgins, S. (1995). Ventral frontal deficits in psychopathy: Neuropsychological test findings. Neuropsychologia, 33, 139-151. doi:10.1016/0028-3932(94)00110-B

Larsen, R. J., \& Ketelaar, T. (1991). Personality and susceptibility to positive and negative emotional states. Journal of Personality \& Social Psychology, 61, 132-140. doi:10.1037/0022-3514.61.1.132

Lévesque, J., Eugene, F., Joanette, Y., Paquette, V., Mensour, B., Beaudoin, G., ET AL. (2003). Neural circuitry underlying voluntary suppression of sadness. Biological Psychiatry, 53, 502-510. doi:10.1016/S0006-3223(02)01817-6

Lilienfeld, S. O., \& ANDREWs, B. P. (1996). Development and preliminary validation of a self-report measure of psychopathic personality traits in noncriminal populations. Journal of Personality Assessment, 66, 488-524. doi:10.1207/s15327752jpa6603_3

LYKKEN, D. T. (1957). A study of anxiety in the sociopathic personality. Journal of Abnormal Psychology, 55, 6-10. doi:10.1037/h0047232

Martin, R. C., \& Dahlen, E. R. (2005). Cognitive emotion regulation in the prediction of depression, anxiety, stress, and anger. Personality \& Individual Differences, 39, 1249-1260. doi:10.1016/j.paid.2005.06.004

Moll, J., de Oliveira-Souza, R., Bramati, I. E., \& Grafman, J. (2002). Functional networks in emotional moral and non-moral judgments. NeuroImage, 16, 696-703.

Moll, J., de Oliveira-Souza, R., Eslinger, P. J., Bramati, I. E., Mourao-Miranda, J., Andreiuolo, P. A., \& Pessoa, L. (2002). The neural correlates of moral sensitivity: A functional magnetic resonance imaging investigation of basic and moral emotions. Journal of Neuroscience, 22, 2730-2736.

Moll, J., Zahn, R., De Oliveira-Souza, R., Krueger, F., \& GrafMAN, J. (2005). The neural basis of human moral cognition. Nature Reviews Neuroscience, 6, 799-809.

Müller, J. L., Sommer, M., Wagner, V., Lange, K., Taschler, H., RÖDER, C. H., ET AL. (2003). Abnormalities in emotion processing within cortical and subcortical regions in criminal psychopaths: Evidence from a functional magnetic resonance imaging study using pictures with emotional content. Biological Psychiatry, 54, 152-162. doi:10.1016/S0006-3223(02)01749-3

Nolen-Hoeksema, S., \& CoRte, C. (2004). Gender and self-regulation. In R. F. Baumeister \& K. D. Vohs (Eds.), Handbook of self-regulation: Research, theory, and applications (pp. 411-421). New York: Guilford.

NuCCI, L. P., \& Herman, S. (1982). Behavioral disordered children's conceptions of moral, conventional, and personal issues. Journal of Abnormal Child Psychology, 10, 411-426.

Ochsner, K. N., Bunge, S. A., Gross, J. J., \& Gabrieli, J. D. E. (2002). Rethinking feelings: An fMRI study of the cognitive regulation of emotion. Journal of Cognitive Neuroscience, 4, 1215-1229. doi:10.1162/089892902760807212

OChSNer, K. N., \& Gross, J. J. (2005). The cognitive control of emotion. Trends in Cognitive Sciences, 9, 242-249. doi:10.1016/j tics.2005.03.010

Ochsner, K. N., Ray, R. D., Cooper, J. C., Robertson, E. R., Chopra, S., Gabrieli, J. D. E., \& Gross, J. J. (2004). For better or for worse: Neural systems supporting the cognitive down- and upregulation of negative emotion. NeuroImage, 23, 483-499.

Passingham, R. E. (1987). Two cortical systems for directing movement. Ciba Foundation Symposium, 132, 151-164.

PATRICK, C. J. (1994). Emotion and psychopathy: Startling new insights. Psychophysiology, 31, 319-330. doi:10.1111/j.1469-8986.1994 .tb02440.x

Phan, K. L., Fitzgerald, D. A., Nathan, P. G., Moore, G. T., Uhde, T. W., \& TANCER, M. E. (2005). Neural substrates for voluntary suppression of negative affect: A functional magnetic resonance imaging study. Biological Psychiatry, 57, 210-219. doi:10.1016/j .biopsych.2004.10.030

Prinz, J. (2006). The emotional basis of moral judgments. Philosophical Explorations, 9, 29-43.

Raine, A., Lencz, T., Bihrle, S., LaCasse, L., \& Colletti, P. (2000). Reduced prefrontal gray matter volume and reduced autonomic activity in antisocial personality disorder. Archives of General Psychiatry, 57, 119-127. doi:10.1001/archpsyc.57.2.119

Robertson, D., Snarey, J., Ousley, O., Harenski, K., Bowman, 
F. D., Gilkey, R., \& KILTS, C. (2007). The neural processing of moral sensitivity to issues of justice and care. Neuropsychologia, 45, 755766. doi:10.1016/j.neuropsychologia.2006.08.014

Salovey, P., Hsee, C. K., \& Mayer, J. D. (1993). Emotional intelligence and the self-regulation of affect. In D. M. Wegner \& J. W. Pennebaker (Eds.), Handbook of mental control (pp. 258-277). Upper Saddle River, NJ: Prentice Hall.

Samuels, J., Nestadt, G., Bienvenu, O. J., Costa, P. T., JR., Riddle, M. A., Liang, K. Y., ET AL. (2000). Personality disorders and normal personality dimensions in obsessive-compulsive disorder. British Journal of Psychiatry, 177, 457-462. doi:10.1192/bjp.177.5.457

Schaich Borg, J., Hynes, C., Van Horn, J., Grafton, S., \& SinnottArmstrong, W. (2006). Consequences, action, and intention as factors in moral judgments: An fMRI investigation. Journal of Cognitive Neuroscience, 18, 803-817. doi:10.1162/jocn.2006.18.5.803

Slessareva, E., \& Muraven, M. (2004). Sensitivity to punishment and self-control: The mediating role of emotion. Journal of Personality \& Individual Differences, 36, 307-319. doi:10.1016/S0191 $-8869(03) 00087-4$

SPSS FOR WINDOWS, VerSION I3.o (2004). Chicago: SPSS Inc.

Stark, C. E. L., \& SQuire, L. R. (2001). When zero is not zero: The problem of ambiguous baseline conditions in fMRI. Proceedings of the National Academy of Sciences, 98, 12760-12766.
Strange, B. A., Henson, R. N., Friston, K. J., \& Dolan, R. J. (2000). Brain mechanisms for detecting perceptual, semantic, and emotional deviance. NeuroImage, 12, 425-433.

Verona, E., \& Vitale, J. (2006). Psychopathy in women: Assessment, manifestations, and etiology. In C. J. Patrick (Ed.), Handbook of psychopathy (pp. 415-436). New York: Guilford.

Watson, D., Clark, L. A., \& Tellegen, A. (1988). Development and validation of brief measures of positive and negative affect: The PANAS scales. Journal of Personality \& Social Psychology, 54, 10631070. doi:10.1037/0022-3514.54.6.1063

Worsley, K. J., Marrett, S., Neelin, P., Vandal, A. C., Friston, K. J., \& Evans, A. C. (1996). A unified statistical approach for determining significant signals in images of cerebral activation. Human Brain Mapping, 4, 58-73. doi:10.1002/(SICI)1097-0193(1996)4:1<58::AID -HBM4>3.3.CO;2-L

Yang, Y., Raine, A., Lencz, T., Bihrle, S., LaCasse, L., \& ColLETTI, P. (2005). Volume reduction in prefrontal gray matter in unsuccessful criminal psychopaths. Biological Psychiatry, 57, 1103-1108. doi:10.1016/j.biopsych.2005.01.021

(Manuscript received July 20, 2007; revision accepted for publication July 2, 2008.) 